\title{
Doctoral Training Partnerships: a work-in-progress review of the postgraduate researcher experience
}

\author{
Rebekah Smith McGloin, University of Nottingham
}

\begin{abstract}
Recent changes in research council policy and postgraduate funding have seen the beginnings of a fundamental reconfiguration in how some $\mathrm{PhD}$ students are recruited and trained. This report is a work-in-progress review of early student evaluation data from a single doctoral training partnership (DTP) within this new doctoral training landscape. It gives a broad overview of historical and contemporary challenges in researcher development before summarising the results of evaluation data from the first year of the BBSRC DTP. It goes on to discuss how these preliminary findings might be followed up and what they might hint at in terms of the model's potential to influence researcher development in the future.
\end{abstract}

Keywords: Researcher development; Student experience; Doctoral training

\section{Introduction}

\section{The Doctoral Training Landscape}

The doctoral training landscape is changing for $\mathrm{PhD}$ students. No longer the lone researcher's three-year slog in the isolated laboratory or specialist library. Working towards a $\mathrm{PhD}$ has become, for some, a four-year team pursuit. An ever-increasing number of postgraduate research students (PGRs) are undertaking cohort-based integrated training programmes either before or alongside $\mathrm{PhD}$ research, often working across disciplines and sometimes cross-institutionally, in close collaboration with industry. ${ }^{1}$

\section{The Rise of the Cohort-based Approach}

These new configurations of the traditional $\mathrm{PhD}$ are called Centres for Doctoral Training (CDT) or Doctoral Training Partnerships (DTP) - both cohort-based approaches to recruiting, training and developing postgraduate students. They are a rapidly expanding phenomenon which affects $\sim 20 \%$ of PGRs in most research-intensive universities.

This largely homogeneous population of research-council funded, UK PGRs at Russell-Group institutions are the first generation to experience the effects of research council strategy (in straightened times) to: transfer greater administrative burden to universities; leverage greater matched funding from universities and industry; and to continue to drive forward the researcher development agenda in the post-Roberts funding era.

For them, the stakes are high. CDT/DTP programmes often demand significant additional outputs from students alongside the submission of a high-quality thesis within four years. These 
can include completion of taught and assessed modules, laboratory rotations, placements and industrial visits. Academic and administrative staff are meanwhile often developing systems and processes from tabula rasa and CDT/DTP programmes are being delivered (sometimes crossinstitutionally) ${ }^{2}$ for the first time.

The challenge for universities is to get CDT/DTP programmes right for the students whilst identifying and addressing teething problems in the model and continuing to support the other $\sim 80 \%$ of the postgraduate research population; thereby avoiding the " "two-tiered" approach to delivering PhDs' (Payne, cited in Gibney, 2013).

This article is a preliminary summary of the first-year programme evaluation of 34 PGRs who are registered on the Nottingham BBSRC-funded DTP. The group represents a single example of the cohort-based approach to doctoral training in the Biosciences. The article will set out the key features of the BBSRC DTP at Nottingham, and an overview of relevant policy developments and practice in doctoral training before going on to give a brief outline of the research methods used, the results and possible future broader considerations for researcher development.

\section{Context}

\section{The BBSRC-funded Doctoral Training Partnership at the University of Nottingham}

In March 2012 the Nottingham-Rothamsted DTP was awarded a grant of nearly $£ 6 \mathrm{M}$ under the BBSRC Doctoral Training Partnership scheme. The award runs for three years commencing October 2012 and will support, together with consortial funds, up to 114 four-year studentships across three main research areas: global food security; molecules, cells \& organisms; industrial biotechnology and bioenergy. It has strong and growing links with a range of industry partners mainly through placements and match-funding. The DTP's strategic vision is to develop independent, trained, highly-employable scientists in strategically-important research areas. Its priorities are excellence in: postgraduate research training, cohort development, placements, supervision, recruitment, evaluation and support for international researcher mobility.

Its structure is innovative in comparison with the traditional $\mathrm{PhD}$ model but is somewhat typical of the new approach to doctoral training. All DTP students are registered for four years. They enlist on a common programme of induction and training for the first six months of $\mathrm{PhD}$ study, split equally into high-level modular training and laboratory rotations. After six months they choose their PhD project and begin their research. The DTP training programme continues to support their development as individuals and as a cohort over the remaining 3.5 years with annual Spring Schools. Students must also undertake a three-month placement in their third year. They have access to additional training through the generic training programme run by the central Graduate School.

\section{'Roberts Money’ for Researcher Development and the Challenges Remaining}

Until relatively recently, research-intensive universities have benefited from significant ringfenced funding for researcher development (HM Treasury, 2002). This funding (2004-2011), usually referred to as 'Roberts Money', was a result of a $£ 120$ million investment by Research 
Councils UK which followed the 2002 Roberts Report. The report covered the supply of science, technology, engineering and mathematics skills throughout the education system and made several recommendations relating directly to postgraduate researchers and research staff. The funding catalysed unprecedented growth in the quantity and quality of Graduate School provision.

Although interim and summary RCUK reviews of researcher development programmes developed in this period were very positive (RCUK, 2010), and there are many examples of good practice, there also remain some challenges arising from the practise developed during this time. Of particular relevance in terms of contextualising the potential for change brought about by the DTP/CDT model is the relevance, breadth and tailoring of researcher development in the Roberts era. Three key characteristics of this would be: under-use of needs analysis; over-constraint in programme development by the Joint Skills Statement; and lack of general employer engagement.

Whilst 53\% of organisations undertook training needs analysis in 2004 (RCUK, 2005, p.5), the Database of Practice ${ }^{3}$ showed that training needs analysis accounted for just $7 \%$ of the foci of practice in 2005 (RCUK, 2005, p.6) and less than 4\% in 2013. ${ }^{4}$ Moreover, $75 \%$ of practices registered on the Database of Practice at the time related to cross-HEI rather than disciplinespecific provision (RCUK, 2005, p.5). This figure is $77 \%$ in 2013, although the database is significantly smaller now than it was. ${ }^{4}$

It is also useful to consider how programmes might have been constrained by the codification inherent in the Joint Skills Statement (RCUK, 2001) - a framework which distilled the breadth of skills that researchers were expected to develop into a list of just seven. It is clear from the annual 'Roberts Reports' (RCUK, 2005; 2006; 2007; 2008) and RCUK (2010) that the Joint Skills Statement was, alongside QAA (2004), the main measure against which the range of transferable skills training was developed and judged in this period (Park, 2007, p.5). This may be connected to a general paucity in the Roberts era of researcher development opportunities contextualised to particular research areas (evidenced by the Database of Practice), tailored to specific employment sectors or employer need (RCUK, 2010, p.7) and addressing skills not included in the statement such as: work experience, leadership and management (CIHE, 2010, p.3).

These key historical characteristics are also evidenced in the recent PRES 2013 student survey results (Bennett \& Turner, 2013) ${ }^{5}$ which highlight ongoing challenges with: training needs analysis; ${ }^{6}$ offering postgraduates the opportunity to become involved in the broader research culture $;^{7}$ induction experience, ${ }^{8}$ careers advice and employability. ${ }^{9}$

\section{New model of doctoral training for the post-Roberts era}

Roberts money came to an end in 2011, and the broader impact of the recession ensured that no further funding was forthcoming. RCUK made good on Iain Cameron's promise that 'universities would be expected to fund (researcher development) out of the general block grants for doctoral training provided by the councils' (...) and that 'block grants would (not) be increased to take account of this extra burden. ${ }^{10}$ At such a pivotal moment in the development of doctoral training, early student evaluation can help institutions to consider the new CDT/DTP model not 
only in the context of how it fulfils the research councils requirements for a minority population of PGRs, but also in terms of its capacity to address the broader historical and contemporary challenges in researcher development set out above.

Whilst the summary of the most recent national survey of postgraduate research students asserts at a national level 'only very small differences between the research skills experience of those whose training was provided through a doctoral training centre and those whose was not, with negligible effect sizes,' (Bennett \& Turner, 2013, p.5) the report acknowledges that more detailed analysis is required to look at the effects of the CDT/DTP model. This work in progress summarises initial findings of evaluation activities with 2012/13 DTP student cohort at the University of Nottingham which were designed to examine in a single case study some of the initial challenges and opportunities of the model.

\section{Research Methods}

\section{Sample group}

The research sample group is taken from the first cohort of a DTP; chosen because it is to date the:

- largest DTP group (34 PGRs in first cohort);

- most complex, operating across Faculties of Science, Medical and Health Sciences and Engineering;

- most radical departure from a standard $\mathrm{PhD}$ programme at Nottingham, with six-month laboratory rotations before the $\mathrm{PhD}$ project begins, and a 3-month compulsory placement;

- first to work in collaboration with a research institute (Rothamsted).

\section{Methods for collecting student feedback}

This work in progress reports on the survey responses from year one of the following evaluation strategies:

- Year 1: three 12-question surveys (undertaken at critical progression points i.e. after: induction and preliminary training; completion of laboratory rotations; and the $\mathrm{PhD}$ project has begun)

- Years 2-4: annual online surveys

- Ad hoc focus groups

- Bi-monthly student group meetings (reporting to DTP management committee).

\section{Survey Design and Content}

The survey was designed to collect qualitative and quantitative data on key aspects of the DTP student experience. It focused on: induction, training and connectedness (employer engagement, networking, opportunities for mobility). It was conducted online. Students were able to answer anonymously. The survey was designed to take no more than twenty minutes to complete and 
offered a mixture of open-ended and closed-ended questions with a range of dichotomous, multiple response, 5-point likert scale and free-text answers.

This work-in-progress report gives a brief summary of student evaluation of:

- Quality, relevance and pitch of the training programme;

- Employer engagement with student body;

- Cohort development (in terms of networking with other students researching in relevant areas and also group induction);

- Opportunities for cross-institutional connections.

Further analysis of responses is planned. This will include segmenting respondents according to fee status, academic background and career aspirations. It is also the intention to undertake a comparative analysis of data across surveys conducted at different times and between cohorts. Preliminary results suggest a value to further evaluation and analysis of the initial student feedback.

\section{Results}

The average response rate was $82 \%$. Response rates rose steadily during the year.

\section{Quality, relevance and pitch of the training programme}

The DTP training programme is tailored for a biological sciences cohort. It integrates research and generic skills training through a programme of laboratory rotations, taught masters courses and bespoke training. All students participate in mandatory training needs analysis, based on the Researcher Development Framework. The majority of training is elective. The programme is front-loaded into the first six-months and thereafter concentrated mainly into an annual Spring School. Attendance at the Spring School is mandatory for reasons of cohort development. Training is delivered by a combination of Graduate School staff, academics in relevant Schools and guest speakers from other universities and industry.

The majority of students (93\%) agreed or strongly agreed that the training was high quality and relevant to their interests and experience. The exceptions to this were where existing Graduate School generic courses were delivered unedited or where students were invited to attend existing masters-level lectures. Here feedback highlighted similar concerns to the PRES survey around relevance and pitch. In terms of future programme development, respondents requested further tailoring of generic training. They suggested students in future cohorts could benefit from peerto-peer training so that, for example, the Nature of the PhD and the Supervision Process course could be co-delivered by student/supervisor pairs from the previous year.

\section{Employer engagement with student body}

The DTP model allows for a targeted approach to employer engagement which has the potential to work with specific skills councils (e.g. Cogent) and with relevant Knowledge Transfer Networks (e.g. Biosciences and Chemistry Innovation) to ensure training is relevant to industry 
need and enhances student employability. Industry talks are incorporated into the training programme from an early stage. The programme also includes a mandatory three-month industry placement (PIP).

Baseline data, collected at induction, suggested that a greater proportion of the cohort (85\%) than would normally be expected were considering careers outside of academia post-PhD when they started. This engagement with a range of career options continued through the first year. Respondents reported that the relevance of 'careers sessions' (e.g. CV Workshops, Spin-out company talks) was clearer because they knew from the beginning that they were required to undertake an industry placement. There were also high levels of engagement and satisfaction with the 'PIPs Pack' - information on networking with employers as potential placement hosts.

\section{Cohort development}

The DTP cohort is developed from before induction via social media. It is subsequently cemented in induction and the first period of training and followed up with the Spring School. It is supported by a student society which reports $>80 \%$ group participation. The survey results are unanimous in their support for the value of the cohort which is described as 'helpful for many reasons, social and academic'. Respondents particularly valued peer support in induction; choosing and undertaking laboratory rotations; and transition to the final $\mathrm{PhD}$ project. The cohort is currently playing a role in supporting evaluation processes and progression to year 2 through the confirmation review which students undertake together. It is too early for this to be reflected in evaluation.

\section{Opportunities for cross-institutional connections}

The DTP is a partnership between the University of Nottingham and Rothamsted research institute. This partnership affords students the opportunity to undertake six-week laboratory rotations in the research institute with the expectation that $10-15 \%$ each cohort will remain at Rothamsted to undertake their PhD. The DTP also offers an 'International Pathway' which comprises foreign language training and support for students to undertake an overseas placement.

91\% cohort considered that spending a period of time at another research institution would be valuable to their research and would enhance their employability. $76 \%$ expressed an intention to undertake language training in order to support their mobility as researchers. Students valued 'the links the university has to another research institute' and expressed a desire to 'see more links and opportunities for different fields'.

\section{Future Considerations}

Whilst acknowledging the limitations in scope, the limited size of the data set and the contemporary critical debate that surrounds student-led evaluation that is summarised in Zabaleta (2007) and Edstrom (2008), the summary results from this early review of a single DTP cohort are nevertheless a thought-provoking first step in exploring the potential for the new doctoral 
training model, and in particular for considering how it might address some of the challenges remaining in researcher development in the post-Roberts era.

Further evaluation will be carried out with the 2012/13 cohort as they progress and with subsequent DTP cohorts. There is also scope for developing an institutional evaluation strategy to examine in detail student experience in other CDT/DTP cohorts and compare this with national and institutional PRES findings.

As further evaluation and analysis is carried out, staff involved in researcher development may find it productive to consider two challenges (within the constraints of resources):

1) how individual DTPs could be employed as possible poles for innovation through continued engagement with the student voice; and

2) how doctoral training could be reconfigured for all PGRs in order to deliver bettertailored training programmes, induction and training in broad research area cohorts, capacity-building in postgraduate placements, better engagement with employers and greater PGR mobility.

\section{References}

Bennett, P. and Turner, G. (2013) PRES 2013: Results from the Postgraduate Research Experience Survey. York: HEA. Available online: http://www.heacademy.ac.uk/assets/documents/postgraduate/PRES_2013_UK_report.pdf (accessed 15 November 2013).

CIHE (2010) Talent Fishing: What businesses want from postgraduates. London: CIHE. Available online: http://www.cihe.co.uk/talent-fishing-what-businesses-want-frompostgraduates (accessed 15 November 2013).

Edstrom, K. (2008) 'Doing course evaluation as if learning matters most'. Higher Education Research and Development, 27 (2): 95-106. http://dx.doi.org/10.1080/07294360701805234

Gibney, E. (2013) 'PhD System Risks Leaving Overseas Students out in the Cold'. Times Higher Education, 18 April 2013. Available online: http://www.timeshighereducation.co.uk/news/phdsystem-risks-leaving-overseas-students-in-the-cold/2003277.article (accessed 15 November 2013).

HM Treasury (2002) SET for success: the supply of people with science, technology, engineering and mathematics skills. The report of Sir Gareth Roberts' Review. London: HMT. Available online: http://webarchive.nationalarchives.gov.uk/+/http:/www.hmtreasury.gov.uk/d/robertsreview introch1.pdf (accessed 15 November 2013).

Park, C. (2007) Redefining the Doctorate. York: The Higher Education Academy. Available online: http://www.heacademy.ac.uk/assets/documents/research/redefining the doctorate.pdf (accessed 15 November 2013). 
QAA (2004) Code of practice for the assurance of academic quality and standards in higher education. Section 1: Postgraduate research programmes. Gloucester: QAA. Available online: http://www.qaa.ac.uk/Publications/InformationAndGuidance/Pages/Code-of-practice-section1.aspx (accessed 15 November 2013).

RCUK (2001) Joint Statement of the UK Research Councils' Training Requirements for Research Students. London: RCUK. Available online: http://www.vitae.ac.uk/CMS/files/upload/RCUK-Joint-Skills-Statement-2001.pdf (accessed 15 November 2013).

RCUK (2005) Summary of Research Organisation Reporting on Career Development and Skills (Roberts) Payments 2005. London: RCUK. Available online: http://www.vitae.ac.uk/CMS/files/RCUK-Roberts-reporting-summary-2005.pdf (accessed 15 November 2013).

RCUK (2006) Career Development and Transferable Skills Training Payments: Summary of November 2006 Reporting. London: RCUK. Available online: http://www.vitae.ac.uk/CMS/files/RCUK-Roberts-reporting-summary-2006.pdf (accessed 15 November 2013).

RCUK (2007) Career Development and Transferable Skills Training Payments: Summary of 2007 Reporting. London: RCUK. Available online: http://www.vitae.ac.uk/CMS/files/RCUKRoberts-reporting-summary-2007.pdf (accessed 15 November 2013).

RCUK (2008) Career Development and Transferable Skills Training Payments: Summary of 2008 Reporting. London: RCUK. Available online:

http://www.vitae.ac.uk/CMS/files/upload/policy_forum_summary_of_2008_robert_\%20reportin g_jan2009.pdf (accessed 15 November 2013).

RCUK (2010) Review of progress in implementing the recommendations of Sir Gareth Roberts, regarding employability and career development of PhD students and research staff. London: RCUK. Available online:

http://www.rcuk.ac.uk/documents/researchcareers/IndependentReviewHodge.pdf (accessed 15 November 2013).

Zabaleta, F. (2007) 'The use and misuse of student evaluations of teaching'. Teaching in Higher Education, 12 (1):.55-76. http://dx.doi.org/10.1080/13562510601102131

\section{Notes}

${ }^{1}$ Recent Research Council investment in the four-year cohort-based training programme model demonstrates this point: ESRC $£ 80 \mathrm{~m}$ in 2011; BBSRC $£ 220 \mathrm{~m}$ in 2012; AHRC $£ 164 \mathrm{~m}$ in 2013; NERC $£ 100 \mathrm{~m}$; EPSRC $£ 350 \mathrm{~m}$. There has also been investment in the model by Wellcome Trust and European Union investment through the Marie Curie International Training Network actions. 
${ }^{2}$ There are currently significant numbers of cross-institutional consortia, delivering or preparing to deliver the DTP model: 9/21 ESRC-funded DTCs; 12/14 BBSRC-funded DTPs; 9/11 AHRCfunded DTPs; 9/15 NERC-funded DTPs.

${ }^{3}$ The Database of Practice is a shared online searchable database, created by practitioners within the researcher development sector and hosted by Vitae, which collates examples of practice relating to skills and career development of researchers. At the height of its popularity it contained more than 600 examples of activity from across the UK.

${ }^{4}$ See http://www.vitae.ac.uk/dop (accessed 15 November 2013).

${ }^{5}$ Postgraduate Research Experience Survey (PRES) is a biennial survey undertaken by the Higher Education Academy for participating universities.

${ }^{6}$ The PRES 2013 report suggests some concern over the role of supervisors in identifying training and development needs and moreover the suggestion that some students might be missing out on needs analysis altogether (p.26).

${ }^{7}$ The PRES 2013 report highlights lower agreement rates amongst respondents to the question about opportunities to become involved in the wider research community, beyond their department (p.5).

${ }^{8 ،}$ The sector might usefully focus on improving the induction experience given that $26 \%$ of students did not agree they had received an appropriate induction to their research degree programme' (PRES 2013, p.5).

${ }^{9}$ 'While the proportion of students receiving advice on career options increases with year group it is concerning to find that up to 60\% of students may never have this opportunity.' (PRES 2013, p.5)

${ }^{10}$ Vitae Researcher Development Conference, Warwick University, 9 September, 2011.

\section{About the author}

Dr Rebekah Smith McGloin is the BBSRC Doctoral Training Partnership Manager at The University of Nottingham.

Email: rebekah.smith.mcgloin@ @ottingham.ac.uk 